\title{
The Study Elements and Indicators of Risk Management System for Secondary Schools in Thailand
}

\author{
Methenan Wandee ${ }^{1}$, Chaiyuth Sirisuthi ${ }^{2} \&$ Subunn Leamvijarn $^{2}$ \\ ${ }^{1}$ Major Educational Administration and Development, Mahasarakham University, Thailand \\ ${ }^{2}$ Department of Educational Administration, Faculty of Education, Mahasarakam University, Thailand \\ Correspondence: Ratthasart Panichpongsapak, Major Educational Administration and Development, \\ Mahasarakham University, Thailand. E-mail: rattasart.pa@gmail.com
}

Received: August 22, 2016

doi:10.5539/ies.v10n3p154

\begin{abstract}
The purposes of this research aimed 1) to study the elements and indicators of risk management system for secondary schools in Thailand. 2) to study suitable the elements and indicators of the risk management system for secondary schools in Thailand. 3) to study the results of CFA (Confirmatory Factors Analysis) risk management process of risk management system for secondary schools in Thailand. There were four steps as follows: Stage 1 to study theories and concepts from the documents and research. Stage 2 to synthesize the study of concepts, principles and theories involved in this research from the stage 1. Stage 3 to evaluate and confirm the suitability of the elements and indicators of risk management system for secondary schools in Thailand by 9 experts. And Stage 4 to analyze the elements and indicators of risk management process of risk management system for secondary schools in Thailand by CFA (Confirmatory Factor Analysis). There were 350 samples in this study. The instruments used in this study were questionnaire for 9 experts and questionnaire for CFA. The statistics used for data analysis were mean, standard deviation, Chi-square, GFI, AGFI, SRMR, RMSEA. The findings found that the risk management system for secondary schools in Thailand had four main elements as follows: 1) Input consisted of 5 sub-factors, 13 indicators, 2) Process had 2 dimensions: 2.1) Dimension of the risk management process consisted of 8 sub- elements, 31 indicators, 2.2) Dimension of school burdens consisted of 4 sub-elements, 72 indicators, 3) Outputs and Outcomes consisted of 2 sub-elements, 6 indicators and 4) Feedback consisted of 2 indicators. The results of evaluation and confirmatory the suitability the elements and indicators of risk management system for secondary schools in Thailand by 9 experts found that it was suitable in every items. And the results analyze CFA of the elements and indicators risk management process of risk management system for secondary schools in Thailand revealed that the model is harmonious with empirical data and in 'good' level.
\end{abstract}

Keywords: elements and indicators, risk management system, secondary schools in Thailand

\section{Introduction}

The environmental situation in the current globalization has been changed all the times. The organization management in both public and private must adjust own self to be in harmony with it. That means the organizations have caught up with the changing world and risk management efficiently and effectively (Eiemwijarn, 2005). Risk is an event or occurrence uncertainty or it is not an uncertainty, a peril, or a hazard that it has affected or ruined to target goal in country level, organization level, agency level and personnel level. Risk management of organization is factor management and to control activities of operations process, avoidance assumption, elimination of unacceptable risks of organization in order to adjust the risk level in proper management of future events, assessment, systematic accountability that focus on the target goal of organization center (Maneenark et al., 2005).

In Thailand the risk management is a part of responsibility in public organizations to populations and assets of country (Office the Public Sector Development Commission, 2007). Ministry of Education has defined the inspector general of education to inspect risk management. In 2007, Office of the Permanent Secretary, Ministry of Education selected the success level of risk management system to be a subject of performance evaluation of guarantee of agencies to abide by law within 2001. The public sections had been evaluated the risk and improving internal control system. It was a government policy by ministry inspector had provided the risk 
analysis of good governance in the important government projects. And the results of risk analysis could be attached for annual budgeting in 2008 (Chuaytrakul, 2008). It is concluded that the risk management is essential to public operations and the government has provided it to be a policy for public sectors to abide by concrete policy.

Secondary school is a government organization. There are two education levels of educational management: a) Lower Secondary Education level (Grad 6-9), b) Upper Secondary Education level (Grade 10-12) (Government Gazette, 2003). However, the risk management could be evaluated public performance by guarantee of agencies and the regulations of board auditor found that there were several risk aspects in basic education administration (Office of the Permanent Secretary, Ministry of Education, 2015). i.e. risk of: corruptions, learning and teaching, finance, confidence of education, environment, security management, risk in school level, classroom level and student level (Kullieng, 2007; Chauytrakul, 2008; Janthawee, 2008).

The essential problems of secondary school in Thailand are as follows:

1) Problems on lower educational quality, National Institute of Education Testing Service (Public Organization) abbreviated as "NIETS", Conclusion as the result Ordinary National Education Test (O-NET) of secondary education grades 3 (i.e., Grades 9) and secondary education grades 6 (i.e., Grades 12) lower than standard set (50 percent pass) (NIETS, 2013, 2014, 2015).

2) Problems of educational administration in School include: 1) the issue of decentralization, because of the possibility of educational administration decentralization, 2) the effect of educational commander hierarchy, 3) the delay and wasted resources, because of the decision was not at school, 4) the problem of level positions growing that do not relate to the performance of the organization. The restructuring causes many positions and policies lead to the disruptions in the coordination and decreases quality of education. 5) There was corruption that using power to abuse and fraud, 6) the problem of insufficient participation and monitoring by the public (Suntrayuth, 2007)

3) Problem on Human Resources involved in school include: 1) many of school administrators didn't acquire proper qualifications such as the lack of academic leadership, lack of administration skills, lacks of the legitimacy to enter the position. 2) Problem on teacher's quality and readiness such as 2.1) does not change the teaching behavior. 2.2) less knowledge in academic and curriculum 2.3) misunderstanding of child centered approach 2.4) lack of student basic information 2.5) lacks of student caring and parenting 2.6) lesson plan has to be done for teacher's assignment 2.7) lack of teacher research to improve teaching and learning (Suntrayuth, 2007).

4) The students dropout problem: Thailand children enrolled in the education system to complete compulsory education (Secondary Education Grade 3, i.e., Grade 9), just over 70 percent. And completion of basic education (Secondary Education Grade 6, i.e., Grade 12), which means that approximately 60 percent and that more than 40 percent of children who were left dropout. Student dropout refers to students who have already enrolled in school but out of school and cannot return to studied before the end of compulsory education. That was considering information from students under the Office of Basic Education Committee (OBEC), Number of students' dropout academic yearly and according to data from the persistence of students in basic education academic year 2539-2556. Stage of the most dropout was lower secondary education grade 3 (also known as grade 9) to the high school or vocational (Wanagowit, 2014).

5) Other problems: i.e., not attending school, game addict, gambling, adaptation, pregnant in school, drug uses and addicts. (Get-man, Online), Corruptions, learning and teaching, finance, confidence of education, environment, security management, risk in school level, classroom level and student level (Kullieng, 2007; Chauytrakul, 2008; Janthawee, 2008).

According to those problems, there were factors or causes of secondary schools in Thailand could not administrate to achieve the educational goals and objectives to reach the goals in national level, organization level, projects and activities level. The researcher called "The risk of secondary schools in Thailand". To prevent the future risks, school should be decrease risks to the minimum acceptable rate, can be evaluated, monitored, and rechecked for the school achievement in goals and objectives by using the effective and efficient risk management. So the study of elements and indicators of risk management system for secondary schools in Thailand are considered the most important. Thus, researcher interested to conduct research to get answers to questions in this research and to provide a basis on which to develop a risk management system for secondary schools in Thailand and can to administer in risk management in order to control the risk level to be accepted in the goal of organization in terms of evaluation, controlling and accountability systematically. 


\section{Research Questions}

1) What are the elements and indicators of risk management system for secondary schools in Thailand?

2) The elements and indicators of the risk management system for secondary schools in Thailand have appropriate or not, and how?

3) What are the results of CFA (Confirmatory Factors Analysis) risk management process of risk management system for secondary schools in Thailand?

\section{Purposes of the Research}

1) 3.1 To study the elements and indicators of risk management system for secondary schools in Thailand.

2) 3.2 To study suitable the elements and indicators of the risk management system for secondary schools in Thailand.

3) 3.3 To study the results of CFA (Confirmatory Factors Analysis) risk management process of risk management system for secondary schools in Thailand.

\section{Methods and/or Techniques}

\subsection{Research Design}

The Study Elements and Indicators of Risk Management System for Secondary Schools in Thailand

There were four steps as follows.

Stage 1: To study theories and concepts from the documents and research involved as follows:

To study the system theory as Bertalanffy (1968), Schoderbek and Kefalas (1990). Lunenburg and Omstein (1996), Katz and Kahn (1978), Bureepakdee (2005), Tedsabutra (2011), Srisaenpang (2013), Patthanajureepan (2013) and Montree (2015). The study result was concluded that the system consisted of four main elements i.e. 1) inputs, 2) process/sub systems, 3) outputs and outcomes, and 4) feedback.

To study the secondary school characteristics as Wonsothorn (2002), Pongsuwan (2004), Sao-pa-yon (2004), The Basic Education Core Curriculum B.E. 2551 (The Ministry of Education, 2003), Chadcham (2004) refer that Secondary schools in Thailand is a system unit that consists of main elements, sub-elements and indicators under a unit. It is an educational management unit in Mathayomsuksa 1-6 (i.e., Grade 7-12), Under Office of the Basic Education Commission. The characteristic of educational management is a system approach including with inputs, process/sub-systems, outputs and outcomes, and use the feedbacks It is a guideline as a manual of basic school management to develop and improve education system, the workload of school. To study frameworks of secondary schools in Thailand from the handbook on administration of Basic Education institutions as Juristic schools (Government Gazette, 2007; The Ministry of Education, 2003). To know about the burdens of secondary schools in Thailand. The conclusions found that the burdens of secondary schools in Thailand have four sections: an academic management section including with 15 jobs, budge management section including with 22 jobs, human resources management section including with 16 jobs and general management section including with 18 jobs. To study the risk management as Wilson (1999), Australia and New Zealand 4368: AS/NZ (2003), Gray and Larson (2006), International Organization Standard: ISO 31000 (2009), Committee of Sponsoring Organizations of the Treadway Commission: COSO (2007) refer that the risk management consisted of 8 steps: 1) Risk Awareness (RA), 2) Organization Analysis (OA), 3) Objective Setting (OS), 4) Risk Identification (RI), 5) Risk Evaluation (RE), 6) Risk Response (RR), 7) Monitoring and Evaluation (ME) and 8) Reporting and Guide (RG). Furthermore, the researcher had studied risk education in schools under the Basic Education in the researches and suggestions as Kullieng (2007), Chauytrakul (2008), Janthawee (2008), Srisaenpang (2013), Patthanajureepan (2013). The study concluded that the risk of basic secondary school occurred in four sections: 1) an academic management, 2) budget management, 3) human resources management and 4) general management.

Stage 2: To synthesize the study of concepts, principles and theories involved in this research from the stage 1, this stage aimed to define the elements and indicators of risk management system for secondary schools in Thailand.

Stage 3: To evaluate and confirm the suitability of the elements and indicators of risk management system for secondary schools in Thailand by 9 experts. These field experts consisted of 4 experts in risk management and 5 experts in school management.

Stage 4: To analyze the elements and indicators risk management process of risk management system for secondary schools in Thailand by CFA (Confirmatory Factor Analysis). Assure the harmonious of fit between 
empirical data results from the study on elements and indicators and model.

\subsection{Sample Group}

Sample group for CFA consisted of 350 samples from 100 secondary schools in Thailand, 3-4 samples from each school consisting of a school director, a school head of Internal Control, and 1-2 teacher school. Purposive Sampling was applied for selecting sample schools. The selected schools consisted of 35 schools located in Buriram province, 35 schools located in Nakhon-ratchasima province, 30 schools located in Surin province.

\subsection{Instruments Used for Data Collection}

Designed and developed by the researcher as follows.

A questionnaire for suitability of elements and indicators of risk management system for secondary schools in Thailand was applied for data collection. The instrument used was a questionnaire applied. There are 124 questions and IOC between 0.67-1.00.

A questionnaire for analyze the elements and indicators of risk management process of risk management system for secondary schools in Thailand by CFA (Confirmatory Factor Analysis). The instrument used was a 5 rating-scale questionnaire, 31 questions. IOC $=1$, the discrimination of each question used was t-test. Every item was $t$ value $>1.75$. The reliability of whole questionnaire was a value of Alpha-Coefficient: $(\alpha) .96$.

\subsection{Data Collection}

A letter requesting the cooperation in providing research data issued by the Faculty of Education, Mahasakham University and questionnaires were returned to the researcher within 30 working days. For those which had not been returned on the stated date, the researcher went to the sample schools in person to get the completed questionnaires. Total completed questionnaires received were 350 .

\subsection{Data Analysis}

The data analysis of experts' questionnaire was analyzed by Index of Item Objective Congruence: (IOC) (Rovinelli and Hambleton, 1977), between the questions and definition indicators of main elements and sub-elements. These were defined IOC in 0.05 up, It showed that the questions had congruence with definition and suitability.

The analyze of confirmatory the elements risk management process of risk management system for secondary schools in Thailand by computer program was applied by Confirmatory Factor Analysis (CFA) checked model validity with empirical data (Chadcham \& Korpech-pranee, 2003). Statistics for da ta analysis by chi-square: Relative chi-square $(\mathrm{CMIN} / \mathrm{df})<3.00$, Goodness of Fit Index $(\mathrm{GFI})>.90$, Adjusted goodness of fit index $(\mathrm{AGFI})>.90$, Comparative fit index $(\mathrm{CFI})>.95$. These were model theory measuring congruence with empirical data. If Standardized root mean square resident (SRMR) was a value lower than 0.08 , it showed that the model given would be congruence with data well. And root mean square error approximation (RMSEA) was a value lower than $<0.06$, it demonstrated that the model given would be congruence with data well.

\section{Results}

The findings of this research were answered according to the research questions as follows:

\subsection{What Are the Elements and Indicators of Risk Management System for Secondary Schools in Thailand?}

Step 1. The results of studying principles, concepts and theories involved as the conclusion as follows:

The system consisted of four main elements: 1) Inputs, 2) Process/ sub-systems, 3) Outputs/outcomes and 4) Feedback.

The secondary schools in Thailand characteristic is an educational management organization including with teaching in Mathayomsuksa 1-6 (i.e., Grade 7-12), Under the Office of the Basic Education Commission. There is an education management a system approach that the inputs get through process and sub-systems, and finally get the outputs and outcomes and feedbacks that is a guideline to develop and improve organization administration. The framework of burdens management have four sections: 1) an academic management section including 15 jobs, 2) budget management section including 22 jobs, 3) human resources management section including 16 jobs, and 4) general management section including 18 jobs.

Risk Management consisted of 8 steps: 1) Risk Awareness (RA), 2) Organization Analysis (OA), 3) Objective Setting (OS), 4) Risk Identification (RI), 5) Risk Evaluation (RE), 6) Risk Response (RR), 7) Monitoring and Evaluation (AE), 8) Reporting and Guide (RG). Risk of secondary schools in Thailand is a risk in four burden sections: 1) academic management section, 2) budget management section, 3) human resources management 
section, and 4) general management section.

Step 2. The results of synthesis the principles, concepts and theories involved from the step 1.

The risk management system for secondary schools in Thailand consisted of 4 main elements, 19 sub-elements and including 124 indicators as the Figure 1 below within the following details.

According to the Figure 1: risk management system for secondary schools in Thailand consisted of 4 main-elements, 19 sub-elements, and including with 124 indicators as follows:

Main element 1: Inputs consisted of 5 sub elements including with 13 indicators as follows:

1) Human resources had three indicators: 1) administrator, 2) teachers and 3) students.

2) Objects and technology resources had two indicators: 1) learning buildings including with laboratories, hall, sport building, drinking building, toilet or restroom, library learning sources, 2) technologies including with computers, projectors, overheads, TV, internet and network system.

3) Budget had two indicators: 1) budgets of government fund for education, 2) budgets of non-government funds.

4) Curriculum had two indicators: 1) The Basic Education Core Curriculum B.E. 2551 (A.D. 2008), 2) The School Curriculum.

5) Internal Environment had four indicators: 1) defining policy, vision, mission and strategic plan of school, 2) structure of school management, 3) work culture of school and 4) Data and information for school management.

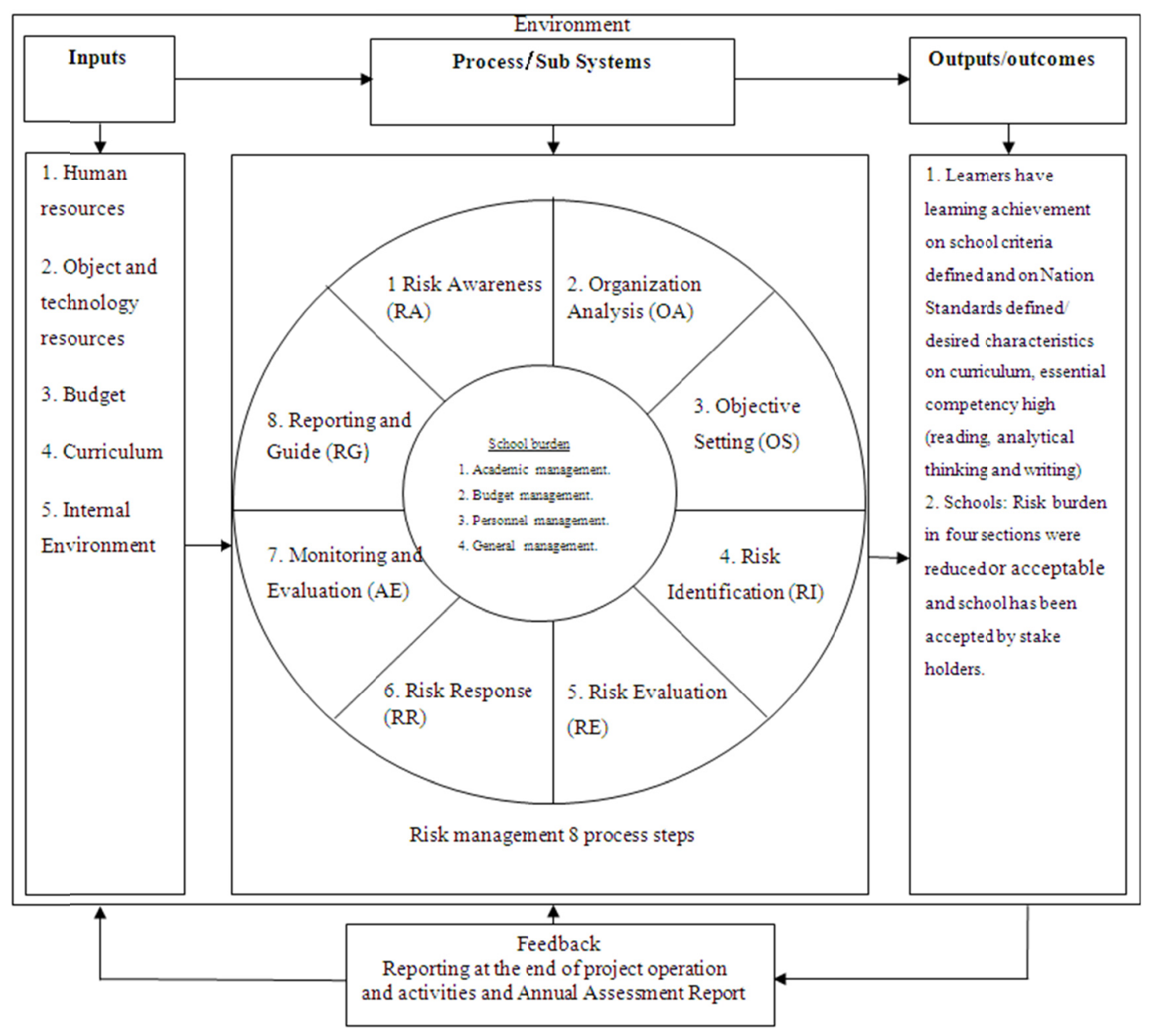

Figure 1. The elements and indicators of risk management system for secondary schools in Thailand 
Main element 2: Process consisted of two dimensions i.e. risk management process and school burden management process.

Dimension of risk management process was administered according to 8 steps, then it got through sub-system of school burden management process in four sections. Risk management process was sub-elements of process that had 8 steps, including with 31 indicators as follows.

Risk Awareness (RA) consisted of 3 indicators: 1) learning, understanding and awareness about risk management for personnel, 2) exchanging information between personnel for making decision on operation of risk management, 3) defining scope of risk management.

Organization Analysis (OA) consisted of 5 indicators: 1) analysis management directions, 2) analysis management structure, 3) analysis problem situation of burdens, 4) analysis internal IT, 5) analysis work culture of personnel.

Objective Setting (OS) consisted of 4 indicators: 1) defining objectives in school or organization level, 2) defining objectives in section level, 3) defining objectives in job level, 4) defining objectives in project and activity.

Risk Identification (RI) consisted of 4 indicators: 1) collecting risks or risk events, 2) identification risks or risk events, 3) discrimination risks, 4) preparation risk lists.

Risk Evaluation (RE) consisted of 3 indicators: 1) defining evaluation criteria of risk, 2) evaluation opportunity and effects of risk, 3) evaluation value of risk level and priority them.

Risk Response (RR) consisted of 5 indicators: 1) defining goal of risk management, 2) determination and making decision to select management measures of risk, 3) planning the management measures selected of risk, 4) proceeding on a plan of management measures selected of risk, 5) defining responsibility person who proceeded on a plan of management measures selected of risk.

Monitoring and Evaluation (AE) consisted of 3 indicators: 1) defining duration of monitoring and evaluation, 2) evaluation after proceeding on plan, 3) reporting monitoring and evaluation.

Reporting and Guide (RG) consisted of 4 indicators: 1) defining a format of risk management report, 2) proceeding a report on a format, 3) disseminating to person involved and public, 4) keeping maintaining the system or improving and developing the system.

Dimension of school burden management process in 4 sections, it was sub-system and sub-element in process that had four sub-elements including with 72 indicators as follows.

Sub-element of sub-system an academic section consisted of 15 indicators: 1) development of school curriculum, 2) planning of academic work, 3) development of indicator learning process, 4) measurement and evaluation and transferring learning unit, 5)research for education development in school, 6) development and supporting learning sources, 7) supervision, 8) guidance, 9) development the internal quality assurance system and education standard, 10) Supporting community to educational strength, 11) coordination to corporately develop academic with other organizations, 12) supporting and enhancing academic work to people, family, organization, company and other educational institutions, 13) providing regulations about academic work of school, 14) selecting reading textbook for education and 15) development usage of medias and technology.

Sub-element of sub system budget section consisted of 22 indicators: 1) the budget plan and the budget request, 2 ) action plan for allocated budgets spending, 3) permission the allocated budgets, 4) transferring and changing the budgets, 5) reporting budgets, 6) checking, following and reporting expense the budgets, 7) fund raising and investment for education, 8) operations according to responsibility about fund for education, 9) resource management for education, 10) planning the supplies, 11) defining list format or features of equipments or budgets constructions 12) development information system and information technology for preparation and purchasing supplies 13) controlling maintenance and available supplies, 14) providing interest from asset, 15) providing the supplies, 16) disbursements from the treasury, 17) receiving money, 18) retention money, 19) payment, 20) delivery money to treasury, 21) financial accounting, 22) reporting finance and financial budget.

Sub-element of sub system human resources section consisted of 16 indicators: 1) manpower planning, 2) allocation of manpower of official and educational personnel, 3) the recruitment and appointment, 4) changing a higher position, 5) migration officials: teacher and administrator, 6) evaluation performance and salary promotion, 7) taking a leave of officials, 8) discipline and punishment, 9) reporting discipline and punishment, 10) personnel system management and personnel record, 11) accounts of name's list and to propose royal insignia to officials, 12) development and supporting academic standing of teachers and educational personnel, 
13) supporting and praising an honor of teachers and educational personnel, 14) supporting professional qualification and professional ethics, 15) enhancing discipline, moral and ethics for teachers and educational personnel, 16) promoting license for professional teaching.

Sub-element of sub system general management section consisted of 18 indicators: 1) developing the IT network system of school to use internal management, 2) coordinating and developing education network, 3) panning education management, 4) research for development policy and plan, 5) arranging the system of management and developing organization, 6) developing standard of performance, 7) using educational technology, 8) applying for students, 9) raising funds for education, 10) field trips, 11) promoting student affairs, 12) educational public relations, 13) promoting and supporting coordination study to people, community and other organizations, 14) coordinating the government in region and local, 15) system management the internal control of department, 16) preparing activities to adjust behavior for student's punishment, 17) proceeding administration jobs, 18) secretarial job of school board.

Main element 3: Outputs and Outcomes consisted of 2 sub-elements including with six indicators.

Sub-element of learners consisted of 3 indicators: 1) learners had essential competency on curriculum in high (reading, analytical thinking and writing), 2) learners had desired characteristics on curriculum, 3) learners had learning achievement on school criteria defined and Education Standards and Quality Assessment defined.

Sub-element of school consisted of 3 indicators: 1) risk burden in four sections were in reduced or acceptable 2) school was approved from stake holder within school, 3) school was approved from stake holder external school.

Main element 4: Feedback consisted of 2 indicators: reporting at the end of project proceeding, 2) reporting annual evaluation.

5.2 The Elements and Indicators of the Risk Management System for Secondary Schools in Thailand Have Appropriate or Not, and How?

Step 3 Checking and confirmatory the suitability of elements and indicators of risk management system for secondary schools in Thailand by 9 experts, it revealed that elements and indicators of risk management system consisted of 4 main elements including with 9 sub elements and 124 indicators were suitability.

5.3 What Are the Results of CFA (Confirmatory Factors Analysis) Risk Management Process of Risk Management System for Secondary Schools in Thailand?

Step 4: The results of analyze elements and indicators of risk management system for secondary schools in Thailand by CFA revealed that the model was harmonious with empirical data as shown in Table 1 .

Table 1. Results of confirmatory factor analysis (CFA) risk management process of risk management system for the secondary schools in Thailand

\begin{tabular}{clccc}
\hline \multicolumn{1}{c}{ Latent variable } & \multicolumn{1}{c}{ Observable variables } & Elements weight & $\mathrm{R}^{2}$ & Elements coefficient \\
\hline & 1. Risk Awareness: (RA) & .711 & .507 & .182 \\
& 2. Organization Analysis: (OA) & .804 & .646 & .046 \\
& 3. Objective Setting: (OS) & .681 & .464 & .153 \\
& 4. Risk Identification: (RI) & .981 & .962 & .061 \\
Risk Management Process & 5. Risk Evaluation: (RE) & .942 & .888 & .015 \\
& 6. Risk Response: (RR) & .927 & .859 & .074 \\
& 7. Monitoring and Evaluation: (ME) & .871 & .758 & .130 \\
& 8.Reporting and Guide: (RG) & .869 & .756 & .132
\end{tabular}

Note. $\mathrm{R}^{2}=$ coefficient of prediction, Chi-square $=378.071, \mathrm{df}=327, \mathrm{pValue}=.027, \mathrm{CMIN} / \mathrm{df}=1.156, \mathrm{GF}=.937$, AGFI $=.904, \mathrm{CFI}=.995, \mathrm{SRMR}=.016, \mathrm{RMSEA}=.021$.

According to Table 1 indicated that there were 8 variables of elements of the risk management process. Considering elements weight in average rating of observable variable was 8 variables in risk management process of risk management system for secondary schools in Thailand, it found that all Elements weight were positive value from .681 to .981 and Coefficient of prediction $\left(\mathrm{R}^{2}\right)$ were positive value from .464 to .962 and Elements coefficient were positive value from .015 to .182 . It showed that the eight observable variables were indicators of results of risk management process for secondary schools in Thailand significantly.

The results of CFA analysis of risk management process model basins on risk management system for secondary 
schools in Thailand revealed that the model was harmonious with empirical data by considering harmonious index value as follows: Chi-square $=378.071, \mathrm{df}=327, \mathrm{pValue}=.027, \mathrm{CMIN} / \mathrm{df}=1.156, \mathrm{GFI}=.937, \mathrm{AGFI}=.904$, $\mathrm{CFI}=.995, \mathrm{SRMR}=.016$, RMSEA $=.021$, it demonstrated that the model of risk management process of risk management system for secondary schools in Thailand in overall image, was harmonious with empirical data well and data resulted from all variable measurement could be applied for analysis for further research study with SEM technique. Risk management process of risk management system for secondary schools in Thailand could be shown in Figure 2.

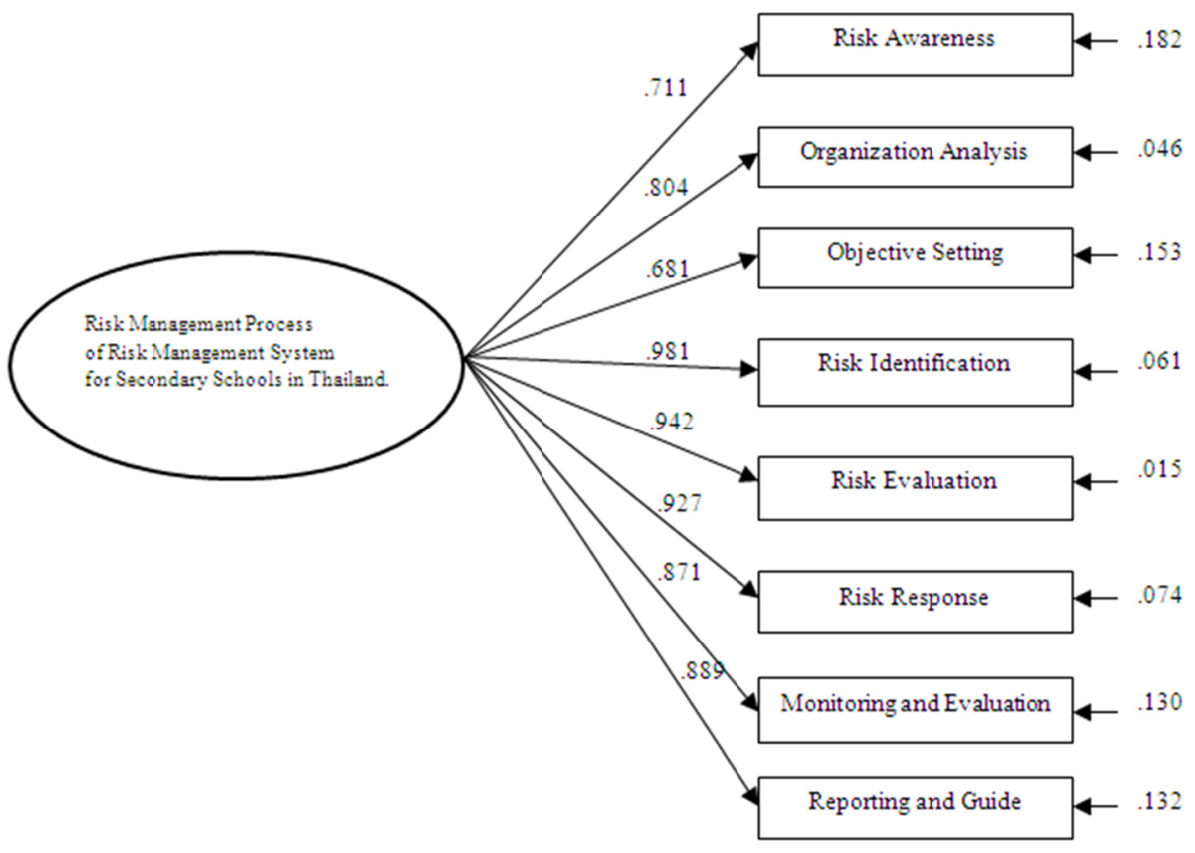

Figure 2. Model of confirmatory factor analysis

\section{Discussion and Conclusions}

Risk management system for secondary schools in Thailand consisted of four main elements as follows.

Main-elements 1: Inputs including with 5 sub-elements and 13 indicators. Main-elements 2: Process had two dimensions: 1) Dimension of risk management process consisted of 8 sub-elements including with 31 indicators; 2) Dimension of school burden management process consisted of 4 sub-systems including with 72 indicators. Main elements 3: Outputs and Outcomes had 2 sub-elements including with 6 indicators. Main elements 4: Feedback had 2 indicators as Bertalanffy (1968), Brittel (1978), Srisaenpang (2013), Patthanajureepan (2013), and Montree (2015) told the concepts about basic elements of system. System elements could consider from the basic systems framework that consisted of main elements 4 sections i.e. Inputs, Process/ sub-systems, Outputs and Feedback. However, the scholars had different concepts from above as Katz and Kahn (1978), Smith (1982), Schoderbek and Kefatas (1990), and Lunenburg and Omstein (1996). There were the elements of external environment i.e. the current of economic, society, politics, and law of politics. It implied that external environment of school or organization could not control and administer, thus, it could not be included in main elements of risk management system for secondary schools in Thailand. Besides, the elements sometimes is called latent variable that could directly be measured. Therefore, it is measured through observed variables or indicators. As Chadcham (2004) said that indicators could indicate to exist of elements or latent variable.

Secondary school characteristic is an organization of basic educational management in Mathayomsuksa 1-6 (i.e. Grade7-12), Office of the Basic Education Commission that administers in system approach including with Input, Process/Sub-systems, Outputs/Outcomes and Feedback for guiding development and improving organization management. This is because secondary school had human resources, object and technology resources, budget, curriculum, inputs as an external environment in organization. And Inputs got into the system through process and sub-system of four work sections: an academic, budget, human resources, and general management in order to get Outputs and Outcomes according to system provided as follows: 1) For four burdens had achieved on 
objectives or risk of four burdens had reduced or acceptable, 2) learners had learning achievement and learners had desired characteristics on curriculum and essential competency in higher reading, analytical thinking and writing, 3) school had been approved by stake holders and had been reported performance at the end of projects, Activities, And an annual reporting was a Feedback for guiding development and improvement organization as Wong-so-thorn (2002), Sara-ratana (2003), Pongsuwan (2004) and Pong-sao-pa-yon (2004).

Risk management process of risk management system for secondary schools in Thailand consisted of 8 steps: 1) Risk Awareness (RA), 2) Organization Analysis (OA), 3) Objective Setting (OS), 4) Risk Identification (RI), 5) Risk Evaluation (RE), 6) Risk Response (RR), 7) Monitoring and Evaluation (ME), 8) Reporting and Guide (RG), as a whole they were relevant to risk management process according to standard of COSO, ERM (2007) that had eight factors of risk management i.e. 1) Internal environment of organization, 2) Objective Setting, 3) Event Identification, 4) Risk Evaluation, 5) Risk Response, 6) Activities Control, 7) Information and Communication, 8) Following up and Evaluation. As AS/NZ 4360 (2004), ISO 31000 (2009) revealed that there were 7 elements of risk management: 1) Risk Communication and Consultant, 2) Risk Context Setting, 3) Risk Identification, 4) Risk Analysis, 5) Risk Evaluation, 6) Risk Response, 7) Following up and Revising. Risk management process of risk management system for secondary schools in Thailand would drive through sub-system of four burdens: 1) an academic management section, 2) budget management section, 3) human resources management section, and 4) general management section in order to achieve to outputs and outcomes i.e. 1) Four burdens could achieve the goal or reduce the risk until organization cloud accept, 2) learners had increased learning achievement, desired characteristics on curriculum, essential competency in high reading, analytical thinking and writing, 3) school had approved by stake holders. As Handbook on Administration of Basic Education Institutions as Juristic Schools Administration (Ministry of Education, 2003), Regulations of Ministry in Criteria Setting and Decentralization Approaches of Administration and Educational management B.E 2550 (2007) (Government Gazette, 2007).

The results of checking and confirmatory the suitability of elements and indicators of risk management system for secondary schools in Thailand by 9 experts, there were four main elements including 19 sub-elements and 124 indicators that were suitable with risk management system for secondary schools in Thailand as the concepts of Bertalanffy (1986), Brittel (1978), Srisaenpang (2013), Patthanajureepan (2013), Montree (2015), Risk Management of COSO (2007), ISO 3100 (2009), and Regulations of Ministry in Criteria Setting and Decentralization Approaches of Administration and Educational management B.E 2550 (2007).

The results of Confirmatory Factor Analysis (CFA) to risk management process model of risk management system for secondary schools in Thailand found that the model was harmonious with empirical data by considering harmonious index value as follows: Chi-square $=378.071, \mathrm{df}=327$, $\mathrm{pValue}=.027, \mathrm{CMIN} / \mathrm{df}=1.156$, $\mathrm{GFI}=.937$, AGFI $=.904, \mathrm{CFI}=.995$, SRMR=.016, RMSEA $=.021$, it demonstrated that the model of risk management process of risk management system for secondary schools in Thailand was harmonious with empirical data well. This implied that the researcher had studied documents involved in CFA in both Thailand and foreign country as follows: 1) Measurement Model, 2) Steps of CFA: defining information of Model specification, Model identification, Parameter estimate, Assessing measurement model validity so as to be a guideline planning to set population and subjects of the study for collecting data. Then, data collection was analyzed, checked congruence of mode in order to confirm that measurement theory produced was harmonious with empirical data by considering Chi-square value, Goodness of Fit Index (GFI), Adjust goodness of Fit Index AGFI), Comparative Fit of Approximation (RMSEA) as Chadcham and Korpechpranee (2003). Proposed that GFI, AGFI and CFI $>.90-.95$ was the measurement theory model that was harmonious with empirical data. However, RMSEA was $<0.05-0.08$, it showed that model was harmonious with data well. Congruence in each variable was considered the relation between observed variables and latent variables or factor loading. In general, the factor loading (elements weight) accepted was 5 up. As Hair et al. (2010) said that all factor loading (elements weight) were positive value from .681 to .981 as shown in Table 1 and Figure 2.

\section{Acknowledgments}

The researcher thank experts, director, head of school planning and/or head of internal control school, teachers of secondary schools in Thailand. I greatly thank Asst. Prof. Dr. Sirisuthi, at Department of Educational Administration, Faculty of Education, Mahasarakham University and Asso. Prof. Dr. Ieamvijarn, at Faculty of Accountancy and Management, Mahasarakham University, Professor Dr. Kowat Thadsabutra, at Department of Educational Administration, Faculty of Education, Mahasarakham who provided insight and expertise that greatly assisted the research and had provided helpful advice and help in the preparation of the article. 


\section{References}

Australia and New Zealand 4360: AS/NZS 4360. (2004). Tutorial: Risk Management Standard. Retrieved from http://www.ucop.edu/enterprise-risk-management/_file/asnzs_4630_2004_tut_notes.pdf

Bertalanffy, A. G. (1968). General System Theory. New York: McGraw Hill.

Brittle, L. R. (1978). Encyclopedia of Profession Management. New York: McGraw Hill.

Buripakdee. (2005). Theory System and Sustainable Development, Public Relation Center, Office of Rajaphat Institution. Bangkok: LT Press.

Chadchaem, S., \& Korphechpranee, S. (2003). Structural equation modeling. Education Research and Measurement Journal, 1(1), 11. Retrieved from http://digital_collect.lib.buu.ac.th/ojs/index.php/search/ issue $/$ view $/ 35$

Chauytrakul. (2008). Risk Management in School of Basic Education Level (Doctoral degree, Ph.D., Mahasarakham University).

Committee of Sponsoring Organizations of the Tread Way Commission (COSO). (2004). Enterprise Risk Management-Integrated Framework: Executive Summary.

Cronbach, L. J. (1970). Essential of Psychological Test (5th ed.). New York: Harper Collins.

Eiemwijarn, S. (2005). University of Thailand with change management. Journal of Graduate Studies, 2(8) 39-56. Retrieved from http://www.mahalib.msu.ac.th/arec/dublin.php?ID $=13400046210$

Hair, J. W. C., Barbin, B. J., Adrson, R. E., \& Tatham, R. L. (2010). Multivariate Data Analysis (pp. 168-707). New Jersy: Upper Sandle River, Hall.

International Organization for Standardization: ISO 3100. (2009). Risk Management-Principles and Guidelines. Retrieved from http://en.wikipedia.org/wiki/Risk_management

Janthawee. (2010). Development Evaluation System and Controlling Educational Risk for School: Empowering Evaluation (Doctoral degree, Ph.D., Mahasarakham University).

Katz, D., \& Kahn L. R. (1978). The Social Psychology of Organization (2nd ed.). New York: John Wiley and Sons.

Kullieng. (2007). Model of Risk Management for Protection Corruption in Basic Schools (Doctoral degree, Ph.D., Administration Department, Faculty of Education, Naresuan University).

Lunenburg, F. C., \& Omstein, A. C. (1996). Educational Administration: Concepts and Practices (2nd ed.). Belmont, CA: Wadsworth Publishing.

Maneenak et al. (2005). Risk Management in Organization Level from Theory to Practice. Bangkok: Printing Final Company.

Ministry of Education. (2003). Handbook on Administration of Basic Education Institutions as Juristic Schools. Bangkok: Ladpraw Publisher.

Montree. (2015). A study on components of internal control - based administrative system in secondary school. Academic Jounals, 10, 2617-2623. https://doi.org/10.5897/ERR2015.2434

National Institute of Education Testing Service (Public Organization) abbreviated as "NIETS". (2014). Report of the ordinary National Education Test (O-NET) Academic Year 2013. Retrieved from http://www.onetresult.niets.or.th/AnnouncementWeb/Login.aspx/

National Institute of Education Testing Service (Public Organization) abbreviated as "NIETS". (2015). Report of the ordinary National Education Test (O-NET) Academic Year 2014. Retrieved from http://www.onetresult.niets.or.th/AnnouncementWeb/Login.aspx

National Institute of Education Testing Service (Public Organization) abbreviated as "NIETS". (2016). Report of the ordinary National Education Test (O-NET) Academic Year 2015. Retrieved from http://www.onetresult.niets.or.th/AnnouncementWeb/Login.aspx/

Office of the Permanent Secretary, Ministry of Education. The Inspector General of the Ministry of Education, usually case, around 1, annual budget B.C. 2558 (2015). 14th Inspection Region. Retrieved from http://www.reo14.moe.go.th/index.php/... /.../1472----1---2558-14

Office the Public Sector Development Commission. (2007). Analysis and Risk Management. http://www.opdc.go.th 
Parinya-Meesuk. (2009). The Effects of Design Participatory Profession Development Program of Teachers (Doctoral degree, Ed.D., Chulalongkorn University).

Patthanajureerat. (2013). Development Risk Management System for Private School, General Education (Doctoral Degree, Ed.D., Mahasarakham University).

Pong-su-wan. (2004). Education Administration in Changing Wave. Burirm: Winai Press.

Regulations of Ministry in Criteria Setting and Decentralization Approaches of Administration and Educational management 2007. (2007, 16 May). The Gazette. Book now at 124. 24 g. p. 1-5.

Rovinelli, R. J., \& Hambleton, R. K. (1977). On the Use of Content Specialists in the Assessment of Criterion-Referenced Test Item Validity. Dutch Journal of Educational Research, 2, 49-60.

Sao-pa-yon. (2004). Principles of Education Administration: Theory and Practice Guidelines. Bangkok: Book Point Company LTD.

Sarra-ratana. (2012). Principles of Education Administration. Bangkok: Redforn Creation.

Schoderbek, \& Kafalas, A. G. (1990). Management Systems: Conceptual Considerations. Boston: Richard D. Irwin.

Sirisuth. (2002). Development System. Mahasrakham: Mahasarakham University.

Srisaenpang. (2013). Development Risk Management System in Primary School (Doctoral degree, Ed.D., Mahasarakham University).

Suntrayuth. (2007). Risk management education. Bangkok. Thailand genetic typing.

Thedsabutra. (2011). Manual of Educational Management 0511 902: Applying System Theory in administration and development (Mahasarakham: Education Adminstration Department, Faculty of Education, Mahasarakham University).

Wanagowit. (2014). Critical study of Thailand. Retrieved from http://thaipublica.org/investigations/critical-study -of-thailand/

Wongsothorn. (2002). Comprehensive Subject of Theory and Practice Guideline in Educational Administration. Nonthaburi, Faculty of Education, Sukhothai University.

\section{Copyrights}

Copyright for this article is retained by the author(s), with first publication rights granted to the journal.

This is an open-access article distributed under the terms and conditions of the Creative Commons Attribution license (http://creativecommons.org/licenses/by/4.0/). 